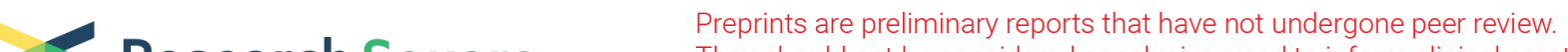 Research Square They should not be considered conclusive, used to inform clinical practice, or referenced by the media as validated information.
}

\section{Endotracheal tube cuff pressure - how fast paramedics can learn the optimal inflation? - comparison of different methods}

Tomasz Piotr Ilczak ( $\square$ tilczak@ath.bielsko.pl )

Akademia Techniczno Humanistyczna w Bielsku-Bialej https://orcid.org/0000-0003-2478-9045

Michal Tomasz Cwiertnia

University of Bielsko-Biala

Piotr Bialon

University of Bielsko-Biala

Michal Szlagor

University of Bielsko-Biala

Beata Kudlacik

University of Bielsko-Biala

Małgorzata Rak

University of Bielsko-Biala

Szymon Bialka

Slaski Uniwersytet Medyczny w Katowicach

Adam Ubych

Slaski Uniwersytet Medyczny w Katowicach

Arkadiusz Stasicki

University of Bielsko-Biala

Wioletta Waksmanska

University of Bielsko-Biala

Jan Bujok

University of Bielsko-Biala

Monika Mikulska

University of Bielsko-Biala

Rafal Bobinski

University of Bielsko-Biala

Marek Stanisław Kawecki

University of Bielsko-Biala 
Keywords: paramedic, intubation, cuff pressure

Posted Date: May 1st, 2020

DOI: https://doi.org/10.21203/rs.3.rs-25600/v1

License: (c) (i) This work is licensed under a Creative Commons Attribution 4.0 International License. Read Full License 


\section{Abstract \\ Background}

Tracheal intubation is the optimal method for opening up the airways. Performed correctly, it prevents stomach contents from entering the respiratory tract, and allows asynchronous CPR to be conducted during sudden cardiac arrest. An important element of correct intubation is proper inflation of the endotracheal tube cuff. Research has shown that when medical personnel use the palpation technique, the cuff is usually inflated incorrectly. This can result in numerous health complications for the patient.

\section{Methods}

This research was conducted in 2020 on a group of paramedics participating in the 15th International Winter Championship of Medical Rescuers in Bielsko-Biała. The aim of the research was to assess two methods of inflating the endotracheal tube cuff. Method A involved inflating the cuff using a syringe and assessing the pressure in the control cuff using the palpation technique. Method B involved inflating the cuff using a manometer. During the inflation, both the cuff inflation pressure and the time required to complete the procedure were recorded. Analysis was also conducted on whether completion of certified ALS and ACLS training had any influence on the effectiveness of the inflation procedure.

\section{Results}

The research showed that paramedics using method $B$ significantly more often inflated the endotracheal tube cuff to the correct pressure than those using method A. However, when method B was used, the procedure took longer to conduct. The study also showed that completion of certified ALS or ACLS training did not have a significant influence on proper inflation of the cuff. Those who had completed certified training courses took significantly longer to inflate the endotracheal tube cuff when using method $A$.

\section{Conclusions}

Inflation of the endotracheal tube cuff by use of a syringe, followed by the palpation technique for assessing the inflation of the cuff balloon is ineffective. Paramedic teams should be equipped with manometers to be used for inflating the endotracheal tube cuff.

\section{Background}

The endotracheal intubation procedure remains the most effective method of opening the airways during pre-hospital treatment. Proper insertion of the endotracheal tube prevents stomach contents from entering the respiratory tract and allows asynchronous cardiac resuscitation to be conducted, which 
minimizes the breaks between chest compressions, thus improving the quality of the resuscitation procedure [1].

An important factor in proper use of endotracheal intubation is correct inflation of the endotracheal tube cuff. The pressure required for correct inflation of the cuff should be in the range of 20 to $30 \mathrm{~cm} \mathrm{H} 2 \mathrm{O}$. Assessment of the correct pressure should be precise and should be carried out using a manometer to indicate the cuff seal inflation pressure. Research in other countries has shown that assessment of cuff inflation using the palpation technique is relatively ineffective and rarely results in correct cuff inflation. Experienced paramedic specialists using the palpation technique to assess the amount of air in the cuff during intensive care conduct the procedure correctly in less than $30 \%$ of cases [2-5]. It has been proven that during palpation assessment, the cuff seal is overinflated, even to as high as $100 \mathrm{~cm} \mathrm{H} 20$ [4].

Application of incorrect pressure in the endotracheal tube cuff seal can be extremely worrying as it may cause numerous complications [6-11]. In pre-hospital paramedic treatment, intubation is often used as the chosen method for clearing the airways. Unfortunately, attention is rarely paid to the correct cuff seal, and instruments for ensuring the seal during the procedure are seldom used. During paramedic treatment, in most cases a syringe is used and the amount of air is assessed using the palpation technique [12]. In this paper, we try to answer the question of what the differences are in the quality of endotracheal tube cuff inflation and the time required for the procedure, depending on whether a syringe or a device for inflating the cuff are used. The aim of the study is to determine the effect of using a device for inflating the endotracheal tube cuff in comparison to the use of a syringe, in terms of the cuff inflation volume and the time required for the procedure. We will also assess the influence of completed certified Advanced Life Support (ALS) and Advanced Cardiovascular Life Support (ACLS) training courses on the achieved inflation volume and the time needed to inflate the cuff.

\section{Methods}

The research was conducted on the 30th January 2020 during a simulated rescue at the 15th International Winter Championship of Medical Rescuers in Bielsko-Biała, Poland. The research involved 108 paramedics working in ambulance response teams. The persons taking part in the research were from 32 ambulance stations from across Poland. Demographic data on the study participants is presented in Table 1 below. All study participants gave informed consent for the study to be carried out. The research was approved by the ethical committee of University in Bielsko-Biała under the reference number RNN/305/2019 - approval 2019/12/7/2.

Table 1. Study group demographic data 


\begin{tabular}{|l|c|c|}
\hline Gender & Frequency - $\mathrm{n}$ & Percentage \\
\hline Male & 100 & $92.60 \%$ \\
\hline Female & 8 & $7.40 \%$ \\
\hline Education & Frequency & Percentage \\
\hline Tertiary & 89 & $82.40 \%$ \\
\hline Secondary & 19 & $17.60 \%$ \\
\hline Work experience & Frequency & Percentage \\
\hline Up to 5 years & 50 & $46.30 \%$ \\
\hline 6 - 8 years & 23 & $21.30 \%$ \\
\hline Over 8 years & 35 & $32.40 \%$ \\
\hline Training & Frequency & Percentage \\
\hline Completed ALS or ACLS & 74 & $68.50 \%$ \\
\hline No training & $34.50 \%$ \\
\hline
\end{tabular}

The study used a simulation technique and was conducted during a simulated rescue in order to maximize the similarity of the procedure to that used in real-life situations. The research was preceded by participants completing a short questionnaire with demographic data and the methods used by the participants for sealing the endotracheal tube cuff in clinical treatment. The procedure was carried out using a SIM Man ALS (Laredal) mannikin, serial number SN.23548170915, an endotracheal ID - 7.5 tube, and a $20 \mathrm{ml}$ syringe and manometer for sealing the VBM (Germany) endotracheal tube cuff. Measurements were also taken using a validated stopwatch by accredited research staff (no. AB1701. Polish Accreditation Center) from the paramedic laboratory at the University in Bielsko-Biała.

The mannikin was correctly intubated by a laboratory technician overseeing the study using an ID 7.5 endotracheal tube and a Mackintosh laryngoscope to a depth of $21 \mathrm{~cm}$, measured from the left corner of the mouth. Every procedure was conducted using a brand-new endotracheal tube, which was inserted into the mannikin's trachea immediately before the cuff was inflated. The study comprised two procedure methods conducted one after the other.

Method $A$ - involved sealing the endotracheal tube cuff using a $20 \mathrm{ml}$ syringe. The time was measured from the moment the syringe was picked up to the moment the cuff inflation procedure was completed and the syringe placed beside the mannikin. Immediately after the procedure was completed, the pressure in the cuff seal was measured using a clock manometer. 
Method $B$ - involved sealing the endotracheal tube cuff using a VBM (Germany) device for inflating the endotracheal tube cuff. The time was measured from the moment the device was picked up to the moment the cuff inflation procedure was completed and the device placed beside the mannikin. Immediately after the procedure was completed, the pressure in the cuff seal was measured.

Analysis was also conducted of the effect of completed certified Advanced Life Support (ALS) or ACLS training courses on the quality of endotracheal tube cuff seal inflation.

All data was entered into a specially prepared Excel 2019 spreadsheet and subjected to statistical analysis.

\section{Statistical Analysis}

The assumed level of significance adopted was $p=0.05$. Variables expressed at the ordinal or nominal level were analyzed using tests based on chi-square distribution. For $2 \times 2$ tables, a continuity correction was applied, while if conditions were not met for the application of a chi-squared test, a precise Fisher test was used and extended for tables larger than $2 \times 2$. Parametric tests were used to analyze quantitative variables divided into groups (the student's T test or ANOVA analysis of variance), or their non-parametric equivalents (the Mann-Whitney U test or the Kruskal-Wallis test). The selection of tests was carried out on the basis of the distribution of the variables, which was verified using the Shapiro-Wilk test. The calculations were conducted using an R statistics environment version 3.6.0, PSPP software and MS Office 2019.

\section{Results}

Analysis of the results obtained during the study should be complemented by key information contained in the questionnaires completed before the procedure was carried out. All the study participants indicated that the method they always used in conducting advanced paramedic treatment was that of inflating the endotracheal tube cuff by syringe. The main determinant they indicated for this choice of method was the time required for carrying out the procedure. None of the study participants gave inflated cuff volume as a condition that determined correct completion of the procedure.

Table 2. Statistical description of analyzed parameters

\begin{tabular}{|l|c|c|c|c|c|c|c|c|}
\hline & $N$ & $M$ & $S D$ & Min & Max & Q25 & Me & Q75 \\
\hline pressure A (cm H2O) & 108 & 83.25 & 35.45 & 8.00 & 120.00 & 55.50 & 93.00 & 120.00 \\
\hline pressure B (cm H2O) & 108 & 26.70 & 3.37 & 20.00 & 30.00 & 24.00 & 28.00 & 30.00 \\
\hline cuff inflation time - Method A & 108 & 7.54 & 3.69 & 3.30 & 24.86 & 5.21 & 6.40 & 8.81 \\
\hline cuff inflation time - Method B & 108 & 9.71 & 3.69 & 4.40 & 22.16 & 7.10 & 8.98 & 10.67 \\
\hline
\end{tabular}


$N$ - amount; $M$ - mean; $S D$ - standard deviation; Min - minimum; Max - maximum; $Q 25$ - first quartile; $M e$ - median; $Q 75$ - third quartile

Table 3. Comparison of Method A and Method B in terms of endotracheal cuff inflation pressure

\begin{tabular}{|c|c|c|c|c|c|c|c|c|}
\hline & & $U$ & $p$ & Min & $\operatorname{Max}$ & Q25 & $M e$ & $Q 75$ \\
\hline \multirow[t]{2}{*}{ Cuff inflation pressure } & Method A (cm H2O) & 1062.00 & $<0.001$ & 8.00 & 120.00 & 55.50 & 93.00 & 120.00 \\
\hline & Method B (cm H2O) & & & 20.00 & 30.00 & 24.00 & 28.00 & 30.00 \\
\hline
\end{tabular}

U - test statistic; p -statistical significance; Me - median; Min - minimum result; Max - maximum result; Q25 - first quartile; Q75 - third quartile

The pressure in cuffs inflated using Method A was significantly higher statistically than in cuffs inflated using Method B $\mathbf{p}<0.05$.

Table 4. Comparison of cuff inflation pressures according to pressure range for both methods

\begin{tabular}{|c|c|c|c|c|c|}
\hline & Method A & Method B & $x 2$ & $d f$ & $p$ \\
\hline Pressure $<20 \mathrm{~cm} \mathrm{H} 20$ & $\begin{array}{c}5 \\
(4.63 \%)\end{array}$ & $\begin{array}{c}0 \\
(0 \%)\end{array}$ & \multirow{3}{*}{193.263} & \multirow{3}{*}{2} & \multirow{3}{*}{$<0.05$} \\
\hline Pressure $20-30 \mathrm{~cm} \mathrm{H} 20$ & $\begin{array}{c}6 \\
(5.56 \%)\end{array}$ & $\begin{array}{c}108 \\
(100 \%)\end{array}$ & & & \\
\hline Pressure $>30 \mathrm{~cm} \mathrm{H} 20$ & $\begin{array}{c}97 \\
(89.81 \%)\end{array}$ & $\begin{array}{c}0 \\
(0 \%)\end{array}$ & & & \\
\hline
\end{tabular}

Inflation of endotracheal tube cuffs using Method A significantly less often statistically resulted in achievement of the required pressure $(20 \mathrm{~cm} \mathrm{H} 20-30 \mathrm{~cm} \mathrm{H} 20)$ than during use of Method B.

Table 5. Comparison of Method A and Method B in terms of endotracheal tube cuff inflation time

\begin{tabular}{|l|c|c|c|c|c|c|c|c|}
\hline \multicolumn{2}{|c|}{} & $U$ & $p$ & Min & Max & Q25 & Me & Q75 \\
\hline \multirow{2}{*}{ Cuff inflation time } & Method A - (sec) & 3324.00 & $<0.001$ & 3.30 & 24.86 & 5.21 & 6.40 & 8.81 \\
\cline { 5 - 9 } & & & 4.40 & 22.16 & 7.10 & 8.98 & 10.67 \\
\cline { 5 - 8 } & Method B - (sec) & & & & & & &
\end{tabular}

U - test statistic; p - statistical significance; Me - median; Min - minimum result; Max - maximum result; Q25 - first quartile; Q75 - third quartile 
The time required to inflated the endotracheal tube cuff using Method B was significantly longer statistically than the time required using Method A $p<0.05$.

Table 6. Comparison of Method A and Method B cuff inflation pressure depending on completed ALS and ACLS training courses

\begin{tabular}{|c|c|c|c|c|c|c|c|c|}
\hline & & $U$ & $p$ & Min & $\operatorname{Max}$ & Q25 & $M e$ & $Q 75$ \\
\hline \multirow[t]{2}{*}{ Method A pressure (cm H2O) } & completed ALS, ACLS & \multirow{2}{*}{1060.00} & \multirow[t]{2}{*}{0.185} & 8.00 & 120.00 & 46.00 & 82.00 & 120.00 \\
\hline & no training & & & 34.00 & 120.00 & 76.50 & 101.00 & 120.00 \\
\hline \multirow[t]{2}{*}{ Method B pressure (cm H2O) } & completed ALS, ACLS & \multirow[t]{2}{*}{1063.50} & \multirow[t]{2}{*}{0.186} & 20.00 & 30.00 & 24.00 & 28.00 & 30.00 \\
\hline & no training & & & 20.00 & 30.00 & 22.50 & 28.00 & 29.50 \\
\hline
\end{tabular}

$U$ - test statistic; $p$ - statistical significance; Me - median; Min - minimum result; Max - maximum result; $Q 25$ - first quartile; $Q 75$ - third quartile

Completion of certified ALS and ACLS training courses did not have a statistically significant influence on correct inflation of the endotracheal tube cuff relative to the method applied $p>0.05$.

Table 7. Comparison of time required for inflation of endotracheal tube cuff relative to the method applied and completed certified training courses

\begin{tabular}{|c|c|c|c|c|c|c|c|c|}
\hline & & $U$ & $p$ & Min & $\operatorname{Max}$ & Q25 & $M e$ & Q75 \\
\hline \multirow{2}{*}{$\begin{array}{c}\text { Time A } \\
\text { (sec) }\end{array}$} & completed training & \multirow[t]{2}{*}{926.50} & \multirow[t]{2}{*}{0.029} & 3.72 & 24.86 & 5.44 & 6.74 & 9.89 \\
\hline & no training & & & 3.30 & 13.24 & 4.75 & 5.92 & 7.34 \\
\hline \multirow[t]{2}{*}{ Time B } & completed training & \multirow[t]{2}{*}{1195.50} & \multirow[t]{2}{*}{0.682} & 4.40 & 21.00 & 7.16 & 8.82 & 10.55 \\
\hline & no training & & & 5.20 & 22.16 & 7.10 & 9.31 & 11.25 \\
\hline \multirow[t]{2}{*}{ Pressure A $(\mathrm{cm} \mathrm{H2O})$} & completed training & \multirow[t]{2}{*}{1060.00} & \multirow[t]{2}{*}{0.185} & 8.00 & 120.00 & 46.00 & 82.00 & 120.00 \\
\hline & no training & & & 34.00 & 120.00 & 76.50 & 101.00 & 120.00 \\
\hline \multirow[t]{2}{*}{ Pressure B } & completed training & \multirow[t]{2}{*}{1063.50} & \multirow[t]{2}{*}{0.186} & 20.00 & 30.00 & 24.00 & 28.00 & 30.00 \\
\hline & no training & & & 20.00 & 30.00 & 22.50 & 28.00 & 29.50 \\
\hline
\end{tabular}

$U$ - test statistic; $p$ - statistical significance; Me - median; Min - minimum result; Max - maximum result; $Q 25$ - first quartile; $Q 75$ - third quartile 
Participants who had completed certified ALS and ACLS training courses took significantly longer to inflate the endotracheal tube cuff using method $A$ than participants who had not completed a training course.

Table 8. Comparison of cuff inflation volume by syringe in relation to completed certified ALS and ACLS training courses

\begin{tabular}{|c|c|c|c|c|c|}
\hline & $\begin{array}{l}\text { Completed ALS/ACLS training } \\
\qquad(\mathrm{n}=74)\end{array}$ & $\begin{array}{l}\text { No ALS/ACLS training } \\
\qquad(\mathrm{n}=34)\end{array}$ & $X^{2}$ & $d f$ & $\mathrm{p}$ \\
\hline Pressure $<20 \mathrm{~cm} \mathrm{H} 20$ & $\begin{array}{c}5 \\
(6.76 \%)\end{array}$ & $\begin{array}{c}0 \\
(0 \%)\end{array}$ & \multirow{3}{*}{5.627} & \multirow{3}{*}{2} & \multirow{3}{*}{0.059} \\
\hline Pressure 20 - $30 \mathrm{~cm} \mathrm{H} 20$ & $\begin{array}{c}6 \\
(8.11 \%)\end{array}$ & $\begin{array}{c}0 \\
(0 \%)\end{array}$ & & & \\
\hline Pressure $>30 \mathrm{~cm} \mathrm{H} 20$ & $\begin{array}{c}63 \\
(85.13 \%)\end{array}$ & $\begin{array}{c}34 \\
(100 \%)\end{array}$ & & & \\
\hline
\end{tabular}

Among the participants in the study group $(n=74)$ who had completed certified ALS or ACLS training, $6.76 \%$ achieved a result of lower than $20 \mathrm{~cm} \mathrm{H} 20,8.11 \%$ achieved a result around the norm, while $85.13 \%$ achieved a result that exceeded a volume of $30 \mathrm{~cm} \mathrm{H2O}$. Among the study group participants $(n=34)$ who had not completed certified training, all achieved a result that exceeded a volume of $30 \mathrm{~cm} \mathrm{H} 2 \mathrm{O}$. Completion of certified training does not therefore have a statistically significant influence on achieving the correct inflation volume of the endotracheal tube cuff $\mathbf{p}=\mathbf{0 . 0 5 9}$.

\section{Discussion}

Inflation of the endotracheal tube cuff can be done using a syringe or by employing a manometer [1214]. The authors of this study analyzed numerous publications that assessed the effectiveness of using a manometer during inflation of the endotracheal tube cuff. In none of these papers was there detailed information on the availability of this type of device among paramedic teams. The questionnaire used in our study showed that during their work in emergency medical teams, none of the study participants uses a manometer to inflate the endotracheal tube cuff. This is explained by the necessity to save time when working in two-person teams.

Inflation of the endotracheal tube cuff to the correct pressure is one of the elements in properly conducted intubation. Carrying out the procedure correctly is difficult when it is done using a syringe [2-5]. Numerous research studies, both in clinical and in simulated conditions, have shown use of a syringe almost always results in excessive inflation of the cuff $[4,5,13,14]$. Over-inflation of the endotracheal tube cuff leads to patient complications in the area of the trachea, resulting in ischemia, infection or 
narrowing of the windpipe [15]. In their research conducted on human corpses, Sudhoff et al. demonstrated that excessive inflation of the endotracheal tube cuff can cause rupture of the trachea [16]. Our research has shown that when paramedics used a manometer, they correctly inflated the endotracheal tube cuff on every occasion, which demonstrates a statistically significant difference between this method and that involving use of a syringe. When a syringe was used, accompanied by assessment of inflation using the palpation method, over inflation occurred in $89 \%$ of cases. In other researches into proper endotracheal tube cuff inflation, authors indicate that too low pressure in the cuff seal can cause complications such as tube displacement or inhalation of stomach contents into the airways [9-11]. Our research showed that insufficient cuff inflation occurred in $4.63 \%$ of cases, and took place only when a syringe was used. Training certified by the AHA and ERC in advanced resuscitation techniques focus on teaching practical skills that can be later used during clinical treatment. This training includes workshops on correctly ensuring and maintaining unobstructed airways [17-20]. Many studies that include an assessment of the correct procedure for maintaining unblocked airways point to the need for improvement in the skills required for proper inflation of the endotracheal tube cuff $[4,5,12,13]$. Our research has proved that participation in certified ALS and ACLS training courses does not have a significant influence on correct inflation of the endotracheal tube cuff, irrespective of which method is used. The research demonstrated that paramedics with an ALS or ACLS course completion certificate took a statistically significant longer time to inflate the cuff by syringe than those who had not completed a training course. This may indicate that in contrast to medical staff who have not completed a training course, paramedics who have completed such a course are more aware of the importance and necessity of correctly inflating the cuff, although unfortunately this is not reflected in achievement of the proper cuff pressure.

\section{Conclusions}

Emergency medical teams should be equipped with devices for inflating the endotracheal tube cuff. The palpation method is ineffective in assessing the proper inflation of the endotracheal tube cuff. More emphasis should be placed on proper inflation of the endotracheal tube cuff during workshops on maintaining unobstructed airways conducted during certified ALS and ACLS training courses.

\section{Abbreviations}

CPR - cardiopulmonary resuscitation

ALS - Advanced Life Support

ACLS - Advanced Cardiovascular Life Support

\section{Declarations}

Ethics approval and consent to participate : 
The research was approved by the ethical committee of University in Bielsko-Biała under the reference number RNN/305/2019 - approval 2019/12/7/2.

\section{Consent for publication :}

Not Apllicable

\section{Availability of data and materials:}

The datasets used and/or analysed during the current study are available from the corresponding author on reasonable request.

\section{Competing interests :}

The authors declare that they have no competing interests.

\section{Funding :}

The study was financed from the funds of the Faculty of Health Sciences University of Bielsko-Biala. This research did not receive any specific grant from funding agencies in the public, commercial, or notfor-profit sectors.

\section{Authors' contributions :}

$T I, M K, M M, W W$, conceived the study, designed the trial, RB,MC,MR,PB,MS, BK,AS,JB supervised the data collection $T I, M M, M R, S B, A U$, provided statistical advice on study design and analysed the data, $M R, T I$ drafted the manuscript, and all authors contributed substantially to its revision

\section{Limitations:}

The study authors are aware that the research has a certain limitation in that it was conducted in simulated conditions on a relatively small group of participants. The research was also conducted using a manometer with a pressure range up to a maximum of $120 \mathrm{~cm} \mathrm{H} 2 \mathrm{O}$, and it was therefore not possible to record higher values. Broader research is planned on a larger group of participants in as realistic conditions as possible.

\section{References}

1. Soar J, Maconochie I, Wyckoff MH, Olasveengen TM, Singletary EM, Greif R, et al. 2019 International Consensus on Cardiopulmonary Resuscitation and Emergency Cardiovascular Care Science With Treatment Recommendations. Resuscitation. 2019 Dec;145:95-150. doi: 10.1016/j.resuscitation.2019.10.016. Epub 2019 Nov 14. - dostęp 09.02.2020

2. Lim H, Kim JH, Kim D, Lee J, Son JS, Kim DC, et al. Tracheal rupture after endotracheal intubation: a report of three cases. Korean J Anesthesiol. 2012 Mar;62(3):277-80 
3. Sengupta P, Sessler DI, Maglinger P, Wells S, Vogt A, Durrani J, et al. Endotracheal tube cuff pressure in three hospitals, and the volume required to produce an appropriate cuff pressure. BMC Anesthesiol. 2004 Nov;4(1):8.

4. Hoffman RJ, Parwani V, Hahn IH. Experienced emergency medicine physicians cannot safely inflate or estimate endotracheal tube cuff pressure using standard techniques. Am J Emerg Med. 2006 Mar; 24(2):139-43.

5. Michlig SA. Anaesthetic staff cannot identify extremely high tracheal tube cuff pressures by palpation of the pilot balloon. Br J Anaesth. 2013 Aug;111(2):300-1.

6. Bouattour K, Prost-Lapeyre A, Hauw-Berlemont C, Diehl J-L, Guerot E. A post-intubation tracheal rupture in intensive care unit. Ann Fr Anesth Reanim 2014; 33:590-592

7. Alvarez-Maldonado P, Vidal E, Ceron-Diaz U. Tracheal ulcers due to endotracheal tube cuff pressure. J Bronchology Interv Pulmonol 2011; 18:288-289

8. Hameed AA, Mohamed H, Al-Mansoori M. Acquired tracheoesophageal fistula due to high intracuff pressure. Ann Thorac Med 2008; 3:23-25

9. Estes RJ, Meduri GU. The pathogenesis of ventilator-associated pneumonia: I. Mechanisms of bacterial transcolonization and airway inoculation. Intensive Care Med 1995; 21:365-383.

10. Hamilton VA, Grap MJ. The role of the endotracheal tube cuff in microaspiration. Heart Lung 2012; 41:167-172.

11. Lau ACW, So HM, Tang SL, Yeung A, Lam SM, Yan WW. Prevention of ventilator-associated pneumonia. Hong Kong Med J 2015; 21:61-68.

12. Peters JH, Hoogerwerf N. Prehospital endotracheal intubation; need for routine cuff pressure measurement? Emerg Med J. 2013 Oct;30(10):851-3. doi: 10.1136/emermed-2012-201388.

13. Harm F, Zuercher M, Bassi M, Ummenhofer W. Prospective observational study on tracheal tube cuff pressures in emergency patients-is neglecting the problem the problem? Scand J Trauma Resusc Emerg Med. 2013 Dec 4;21:83. doi: 10.1186/1757-7241-21-83.

14. Hedberg P, Eklund C, Hogqvist S. Identification of a Very High Cuff Pressure by Manual Palpation of the External Cuff Balloon on an Endotracheal Tube AANA Journal 2015; 83 (3): 179-182.

15. Chan SM, Wong CS, Cherng $\mathrm{CH}$. Determining an optimal tracheal tube cuff pressure by the feel of the pilot balloon: a training course for trainees providing airway care Acta Anaesthesiol Taiwan 2009; 47 (2): 79-83.

16. Sudhoff TH, Seidl RO, Estel B, Coordes A. Clin Exp Otorhinolaryngol 2015; 8 (4): 409-415.

17. Soar J, Nolan JP, Böttiger BW, Perkins GD, Lott C, Carli P, et al. European Resuscitation Council Guidelines for Resuscitation 2015 Section 3. Adult advanced life support. Resuscitation 2015; 95: 100-147.

18. Link MS, Berkow LC, Kudenchuk PJ, Halperin HR, Hess EP, Moitra VK, et al. Part 7: Adult Advanced Cardiovascular Life Support: 2015 American Heart Association Guidelines Update for Cardiopulmonary Resuscitation and Emergency Cardiovascular Care. Circulation 2015; 132: 444-464. 
19. Monsieurs KG, Nolan JP, Bossaert LL, Greif R, Maconochie IK, Nikolaou NI, et al. European Resuscitation Council Guidelines for Resuscitation 2015: Section 1. Executive summary. Resuscitation 2015; 95: 1-80.

20. Neumar RW, Shuster M, Callaway CW, Gent LM, Atkins DL, Bhanji F, et al. Part 1: Executive summary: 2015 American Heart Association Guidelines Update for Cardiopulmonary Resuscitation and Emergency Cardiovascular Care. Circulation 2015; 132: 315-367. 